\title{
The APP-interacting protein FE65 is required for hippocampus-dependent learning and long-term potentiation
}

\author{
Yan Wang, ${ }^{1,2,3,6}$ Ming Zhang, ${ }^{1,2,6}$ Changjong Moon, ${ }^{4}$ Qubai Hu, ${ }^{5}$ Baiping Wang, ${ }^{5}$ \\ George Martin, ${ }^{5}$ Zhongsheng Sun, ${ }^{3,7}$ and Hongbing Wang ${ }^{1,2,7}$ \\ ${ }^{1}$ Department of Physiology, Michigan State University, East Lansing, Michigan 48824, USA; ${ }^{2}$ Neuroscience Program, Michigan \\ State University, East Lansing, Michigan 48824, USA; ${ }^{3}$ Behavioral Genetics Center, Institute of Psychology, Chinese Academy \\ of Science, Beijing 100101, People's Republic of China; ${ }^{4}$ Department of Veterinary Anatomy, College of Veterinary Medicine, \\ Chonnam National University, Gwangju 500-757, South Korea; ${ }^{5}$ Department of Pathology, University of Washington, Seattle, \\ Washington 98195, USA
}

\begin{abstract}
FE65 is expressed predominantly in the brain and interacts with the C-terminal domain of $\beta$-amyloid precursor protein (APP). We examined hippocampus-dependent memory and in vivo long-term potentiation (LTP) at the CAl synapses with isoform-specific FE65 knockout (p97FE65 $5^{-l-}$ ) mice. When examined using the Morris water maze, p97FE65 ${ }^{-I-}$ mice were impaired for the hidden platform task but showed normal performance in the probe test. To further discriminate the role of FE65 in acquisition and memory consolidation, we examined p97FE65 $5^{-I-}$ mice with temporal dissociative passive avoidance (TDPA) and contextual fear conditioning (CFC). p97FE65 ${ }^{-l-}$ mice showed impaired shortterm memory for both TDPA and CFC when tested 10 min after training. After multiple TDPA training sessions, the crossover latency of some p97FE65 $5^{-1}$ mice reached the cutoff value, but it significantly decayed in $8 \mathrm{~d}$. At the Schaffer collateral-CAl synapses, p97FE65 ${ }^{-l-}$ mice showed defective early-phase LTP (E-LTP). These results demonstrate novel roles of FE65 in synaptic plasticity, acquisition, and retention for certain forms of memory formation.
\end{abstract}

[Supplemental material is available online at http://www.learnmem.org.]

FE65 is predominately neurospecific and is expressed in the hippocampus (Kesavapany et al. 2002; Wang et al. 2004a), a brain region involved in certain forms of learning and memory. The gene was first identified as an interaction protein of the $\beta$-amyloid precursor protein (APP) (Fiore et al. 1995). Molecular and cellular studies have revealed several functional domains in FE65. The WW domain is required for interacting with Mena through specific proline-rich motifs (Chen and Sudol 1995; Ermekova et al. 1997), as well as for mediating gene transcription (B Cool, G Zitnik, G Martin, and Q Hu, unpubl.). The second (or more C-terminal) phosphotyrosine interaction (PID) or phosphotyrosine binding (PTB) domain (Bork and Margolis 1995) is required for interacting with the C-terminal of APP (Fiore et al. 1995; Borg et al. 1996; Zambrano et al. 1997). FE65 also interacts with lowdensity lipoprotein-receptor-related protein (LRP) (Kinoshita et al. 2001), ApoE receptor (Hoe et al. 2006), histone acetyl transferase Tip60 (Cao and Sudhof 2001), and transcription factor CP2/LSF/ LBP1 (Zambrano et al. 1998) through its first PID domain. The second PID/PTB domain also binds to the mouse $\beta$-amyloid precursor-like proteins, APLP1 and APLP2 (Bressler et al. 1996).

Several lines of evidence have suggested that a physical interaction between FE65 and APP may be related to the pathogenesis of Alzheimer's disease (AD). First, a mutant form of APP, responsible for some cases of familial $\mathrm{AD}$, shows an altered in vivo interaction with FE65 (Zambrano et al. 1997). Second, it has been demonstrated that APP and FE65 colocalize in the endoplasmic

\footnotetext{
${ }^{6}$ These authors contributed equally to this work.

${ }^{7}$ Corresponding authors.

Email wangho@msu.edu; fax (517) 355-5125.

Email sunzs@psych.ac.cn; fax 86-10-64839916.

Article is online at http://www.learnmem.org/cgi/doi/10.1101//m.1499309.
}

reticulum and Golgi complex, and FE65 facilitates translocation of APP to the cell surface and $\beta$-amyloid secretion (Sabo et al. 1999). Third, decreased levels of the neuronal forms and increased levels of the non-neuronal forms of FE65 are observed in the middle temporal and frontal cortex of $\mathrm{AD}$ brains ( $\mathrm{Hu}$ et al. 2000). Interestingly, the intronic polymorphism of FE65, which leads to the expression of the FE65a2 isoform with lower affinity to APP, associates with resistance to the late onset of $\mathrm{AD}$ (Hu et al. 2002).

In addition to its pathological function in $\mathrm{AD}$, emerging evidence suggests that APP may be an essential molecule for regulating neuroplasticity and neural development (Seabrook et al. 1999). Under nonpathological conditions, APP may play functional roles in axonal transport (Suzuki et al. 2006), neurite growth (Ikin et al. 2007), synapse modification (Sabo et al. 2003), and gene transcription (Muller et al. 2007, 2008). APP knockout (KO) mice display deficits in long-term potentiation (LTP), spatial memory, increased gliosis, and a significant reduction in dendritic length (Dawson et al. 1999; Seabrook et al. 1999), leading to the hypothesis that APP is critical for normal neuronal functions. Furthermore, mice lacking multiple APP family members (APP, APLP1, and APLP2) show cortical dysplasia (Heber et al. 2000). Strikingly, mice lacking multiple FE65 family members (FE65 and FE65L1) show a similar phenotype (Guenette et al. 1996, 2006). These nonpathological functions of APP may be explained by the fact that its natural proteolytic product AICD (APP intracellular domain) confers transcription activity in immortalized cell lines (Cao and Sudhof 2001). Several studies have implicated FE65 in AICD nuclear translocation and AICD-mediated gene transcription (Cao and Sudhof 2001; von Rotz et al. 2004; Muller et al. 2007). However, our recent study suggests that FE65 may regulate transcription independent of AICD (Yang et al. 2006). Due to some similar features shared between APP 
and Notch (Schroeter et al. 1998; Kimberly et al. 2003), it was hypothesized that APP/FE65 may regulate transcription-dependent forms of plasticity, such as long-term memory formation.

Correlated with the phenotypes in APP KO mice, defective hippocampus-dependent memories have been observed with isoform-specific p97FE65 ${ }^{-1-}$ mice, which express only p60FE65 (p60), but not p97FE65 (Wang et al. 2004a). p97 and p60 are possibly generated by alternative translation from the same transcript (Wang et al. 2004a; B Cool, G Zitnik, G Martin, and $\mathrm{Q} \mathrm{Hu}$, unpubl.). p60 is the shorter version of p97, lacks part of the WW domain, and is incapable of activating gene expression (B Cool, G Zitnik, G Martin, and Q Hu, unpubl.). Despite the previous description of p97FE65 function in memory, how it regulates certain processes of plasticity, especially the synaptic function, is largely unknown. It is also not clear whether p97FE65 regulates learning/acquisition or memory retention/consolidation.

In the present study, we examined several forms of hippocampus-dependent memory as well as in vivo LTP with young adult (2- to 4-mo-old) p97FE65 ${ }^{-/}$mice. We demonstrate that p97FE65 ${ }^{-1-}$ mice show major deficits in learning/acquisition for spatial task, temporal dissociative passive avoidance (TDPA), and contextual fear conditioning (CFC). Consistently, p97FE65 ${ }^{-1-}$ mice are defective in early-phase LTP (E-LTP).

\section{Results}

\section{p97FE65 $5^{-I-}$ mice show normal} hippocampus formation

We first examined the overall morphology of the hippocampus of isoformspecific p97FE65 ${ }^{-/-}$mice. Neutral red staining (Supplemental Fig. 1A) and calbindin staining (Supplemental Fig. 1B) revealed no significant difference between wild-type (WT) and p97FE65 ${ }^{-1-}$ mice in gross hippocampal morphology and mossy fiber formation, respectively. Immunostaining for the neuronal and dendritic marker MAP2 also revealed no significant difference in cortex and different areas of the hippocampus including CA1, CA3, and dentate gyrus (Supplemental Fig. 1C). The expression levels of synaptic marker proteins Synapsin I (Supplemental Fig. 1D) and VGAT (Supplemental Fig. 1E) were comparable between WT and p97FE65 $5^{-1-}$ mice. These data, together with a previous report (Wang et al. 2004a), implicate that there is no severe abnormality in hippocampal morphology in p97FE65 $65^{-1-}$ mice.

\section{p97FE65 ${ }^{-1-}$ mice exhibit impaired acquisition, but normal memory retrieval, in the MWM task}

Despite major efforts to probe the function of FE65 in AD pathogenesis, little has been investigated to study plasticity under normal and nonpathological conditions. A previous study documented very interesting memory phenotypes in spatial and associative memory with isoformspecific p97FE65 ${ }^{-1-}$ mice at 14 and $27 \mathrm{mo}$ (Wang et al. 2004a). Due to aging effects on plasticity, the phenotypes observed with aged p97FE65 $5^{-/-}$ mice may be complicated by other factors. In addition, it is not clear whether FE65 regulates learning/acquisition or memory consolidation and retention. Here, we examined several forms of learning and memory with young adult mice (2-4-mo old).

WT and p97FE65 ${ }^{-1-}$ mice were first trained by the visible platform version of the Morris water maze (MWM), during which a visible flag was attached to the platform. Both groups showed significant improvement in escape latency over the training sessions (Fig. 1A), and there was no significant difference between WT and p97FE $65^{-1-}$ mice $\left(F_{(1,20)}=0.12, P=0.5326\right)$. Furthermore, WT and p97FE65 $5^{-1-}$ mice displayed similar swimming speed during visible platform training (Fig. 1B). These results indicate that p97FE $65^{-1-}$ mice are normal in nonspatial learning, motivation, vision, and motor functions.

We then further trained the same animals by a hidden platform task, during which the platform was placed underneath opaque water, and animals learned to use extramaze spatial cues to navigate the circular pool and find the hidden platform. Although both WT and p97FE65 ${ }^{-1-}$ showed significant improvement in escape latency during training $\left(F_{(8,20)}=13.88, P<0.0001\right)$, repeated-measures of two-way ANOVA showed a significant difference between genotypes $\left(F_{(1,20)}=23.45, P<0.0001\right.$; Fig. $\left.1 \mathrm{C}\right)$. There was no significant difference in swimming speed between WT and p97FE65 $5^{-1-}$ mice during the hidden platform training
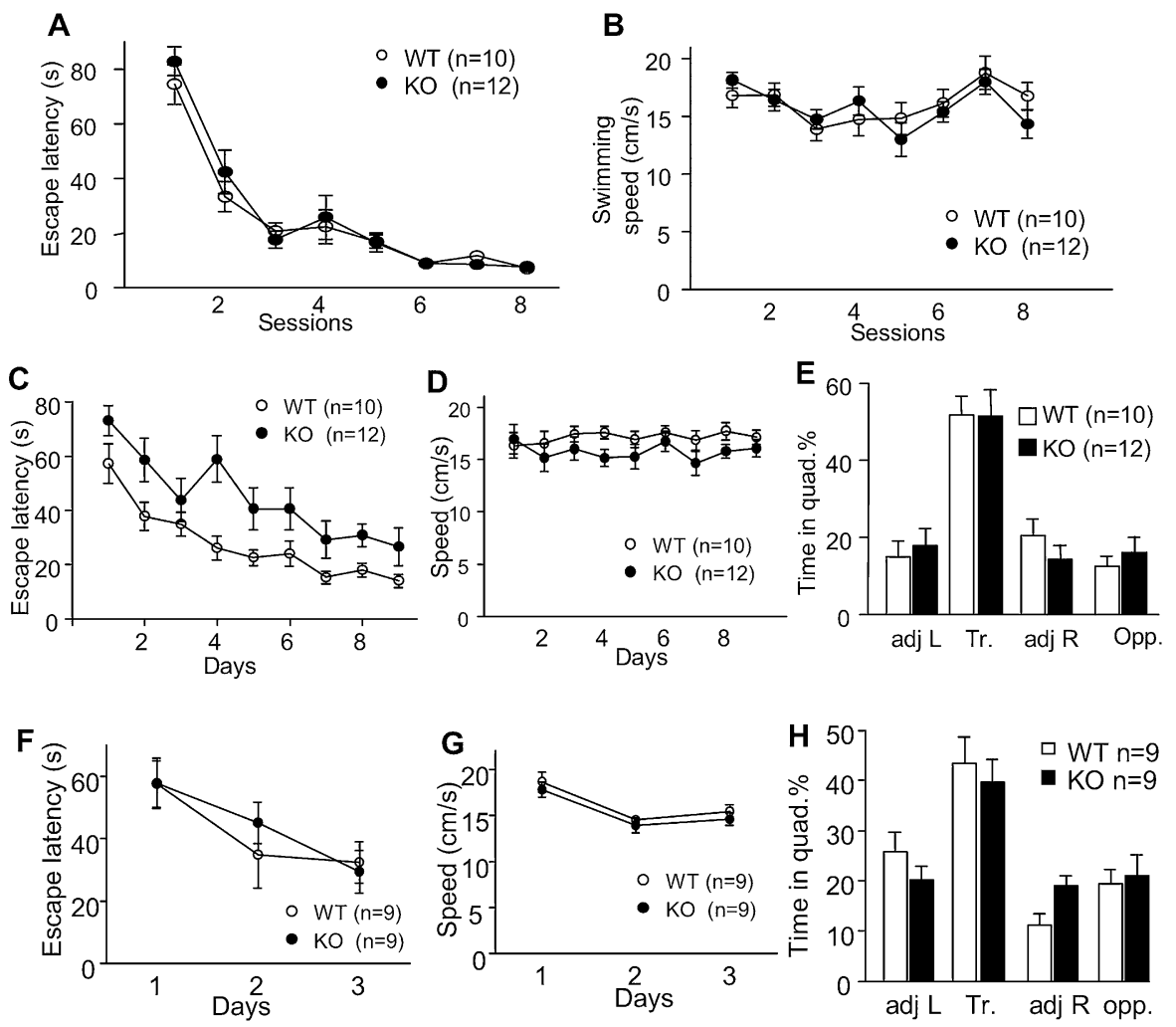

Figure 1. p97FE65 $5^{-1-}$ mice show defective hidden platform learning. $(A)$ Both p97FE65 $5^{-1-}(\mathrm{KO})$ and wild-type (WT) mice show comparable performance during the visible platform training. (B) p97FE65 $5^{-/-}$ mice show comparable swim speed to that of WT mice during the visible platform training. (C) p97FE65 $5^{-1-}$ mice show impaired improvement in escape latency during the hidden platform training. (D) WT and p97FE65 $5^{-1-}$ mice show comparable swimming speed during the hidden platform training. (E) WT and p97FE $65^{-1-}$ mice show comparable time spent in the target quadrant during the probe test. $(F)$ p97FE65 $5^{-1-}$ mice show normal acquisition during the reversal training. (G) WT and p97FE65 ${ }^{-1-}$ mice show comparable swimming speed during the reversal training. $(H)$ p97FE65 ${ }^{-/-}$mice show normal performance in the probe test after reversal training. The probe test was performed $1 \mathrm{~d}$ after the last reversal training session. 
$(P=0.2034$, two-way ANOVA; Fig. 1D). The travel distance for p97FE $65^{-1-}$ mice to find the platform was also significantly longer $\left(F_{(1,160)}=11.27, P=0.0031\right.$; Supplemental Fig. $\left.2 \mathrm{~A}\right)$.

Next, we examined the animals with the probe test, during which the hidden platform was removed. Although the time spent to first reach the hidden platform location was significantly longer for the p97FE65 ${ }^{-1-}$ mice during the probe test $(P<0.01$, data not shown), the two groups showed no significant difference in the percentage of time spent in the target quadrant $(P=0.2594$; Fig. $1 \mathrm{E})$. There was also no significant difference between WT and p97FE65 ${ }^{-/-}$mice in the crossing number for the hidden platform location (data not shown).

We then trained the animals with the reversal paradigm, during which the hidden platform was moved to the opposite quadrant. This task requires the animals to relearn the new platform location and suppress the pre-established memory for the old platform location. As shown in Figure 1F, WT and p97FE65 $5^{-/-}$mice showed a similar decrease in escape latency during the reversal training. WT and $\mathrm{p} 97 \mathrm{FE} 65^{-/-}$mice also showed comparable swimming speed during the reversal training $(P=0.1274$, two-way ANOVA; Fig. $1 G)$, and there was no significant difference in the travel distance either $(P=0.8794$, twoway ANOVA; Supplemental Fig. 2B). When tested by the probe test, both groups showed significant preference for the new platform location $(P<0.05$ for both genotypes; Fig. $1 \mathrm{H})$.

\section{p97FE65 $5^{-1-}$ mice show impaired learning and memory retention in TDPA}

Because p97FE65 ${ }^{-1-}$ mice showed a slower rate of acquisition but normal performance in the probe test, it is possible that FE65 is required for learning rather than consolidation. To further confirm the possibility, we next trained animals with TDPA, during which multiple training sessions were involved and the learning/ acquisition could be better examined. Compared with standard passive avoidance (PA), the animals received a mild electric footshock $10 \mathrm{~min}$ after they crossed over to the dark chamber in the TDPA paradigm. Therefore, the association between the dark chamber (the conditioned stimulus) and the aversive footshock (the unconditioned stimulus) was temporally separated by $10 \mathrm{~min}$. Our previous results have demonstrated that animals gradually improve their crossover latency through the multiple trainings, and the task is dependent on the hippocampus (Zhang et al. 2008). As shown in Figure 2A, p97FE65 ${ }^{-1-}$ mice displayed significantly slower improvement in crossover latency than WT mice during TDPA training $(P<0.05)$. Furthermore, the percentage of animals reaching the cutoff value $(300 \mathrm{sec})$ of crossover latency was higher for WT mice (Fig. 2B). After $5 \mathrm{~d}$ of TDPA training, all WT mice reached the cutoff value when tested on day 6 . Only $60 \%$ of $\mathrm{p} 97 \mathrm{FE} 65^{-1-}$ mice (six out of 10 animals) reached the cutoff value on day 6 . To test long-term memory retention, we selected animals that reached the cutoff value and retested them $8 \mathrm{~d}$ later. As shown in Figure 2C,
p97FE65 $5^{-1-}$ mice showed significant shorter crossover latency, indicating that p97FE65 is required for long-term retention of TDPA memory.

To further examine the ability of learning or acquisition, another cohort of WT and p97FE65 ${ }^{-1-}$ mice was trained by a single TDPA trial and tested shortly (10 min) after the training. As shown in Figure 2D, p97FE65 ${ }^{-1-}$ mice showed significantly shorter crossover latency $\left(F_{(1,26)}=8.12, P=0.0215\right)$. These results demonstrate that p97FE65 ${ }^{-1-}$ mice are defective in learning/acquisition, as well as retention, which may involve both consolidation and reconsolidation. Because p97FE65 ${ }^{-1-}$ mice showed comparable crossover latency to that of WT mice during the first TDPA training session (Fig. 2A,D), it is unlikely that their deficits during testing are attributed to an abnormal preference for darkness. We further performed the dark/light test, during which their preference for the lit and dark chambers was examined (Krishnan et al. 2008). The animals were first placed in the dark chamber; p97FE65 ${ }^{-1-}$ and WT mice displayed a similar latency to cross over to the lit chamber (Fig. 2E). During the 10-min dark/light test, animals were allowed to travel freely between the dark and lit chambers, and the two groups stayed for similar length of time in the lit chamber (Fig. 2F).

\section{p97FE65 ${ }^{-1-}$ mice show impaired acquisition in CFC}

We next examined learning/acquisition by another hippocampus paradigm, CFC. During training, both WT and p97FE65 ${ }^{-1-}$ mice displayed minimal freezing (Fig. 3A). When a brief footshock was delivered, WT and p97FE65 ${ }^{-1-}$ mice showed a similar reaction to the shock, as implied by the increase in velocity during the mild electric shock (Fig. 3B). The similar shock-induced increase in movement velocity demonstrated normal pain sensitivity in
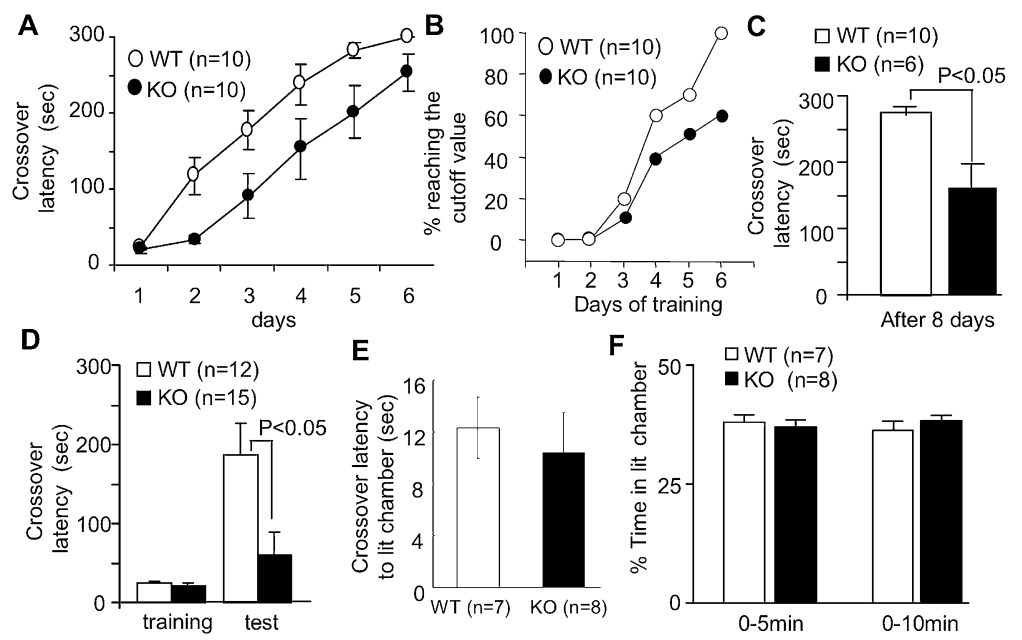

Figure 2. p97FE65 $5^{-1-}$ mice show deficits in TDPA. (A) $\mathrm{p} 97 \mathrm{FE} 65^{-1-}$ (KO) mice show poor improvement in crossover latency during TDPA training. Mice were trained on day 1 and tested daily on days 2-6. From day 2 to day 5, mice were first scored for crossover latency. They then received a mild footshock $10 \mathrm{~min}$ after entering the dark chamber. When a particular mouse reached the $300-\mathrm{sec}$ arbitrary cutoff value, it was not further trained. The value of $300 \mathrm{sec}$ was registered as crossover latency for the test and for all the tests thereafter. $(B)$ The percentage of animals reaching the cutoff value of crossover latency is lower for p97FE65 $5^{-1-}$ mice during whole training sessions. (C) p97FE65 ${ }^{-1-}$ mice show impaired long-term memory retention. After $5 \mathrm{~d}$ of TDPA training, all WT mice reached the $300-$ sec cutoff value. Six out of 10 p97FE $65^{-1-}$ mice also showed crossover latency of 300 sec. These mice were tested $8 \mathrm{~d}$ later to measure their long-term memory retention. For example, if a particular mouse reached the $300 \mathrm{sec}$ value on day 4 , it was further tested on day 12 . (D) p97FE $65^{-/-}$mice show deficits in short-term memory for TDPA. Animals were trained by a single session of TDAP and tested 10 min after the training. ( $E$ ) During the dark/light test, WT and p97FE65 ${ }^{-1-}$ mice showed comparable latency to cross over from the dark chamber to the lit chamber. $(F)$ During the dark/light test, WT and p97FE $65^{-1-}$ mice spent comparable time in the lit chamber. The values for the first 5 min of the entire dark/light test are shown. 

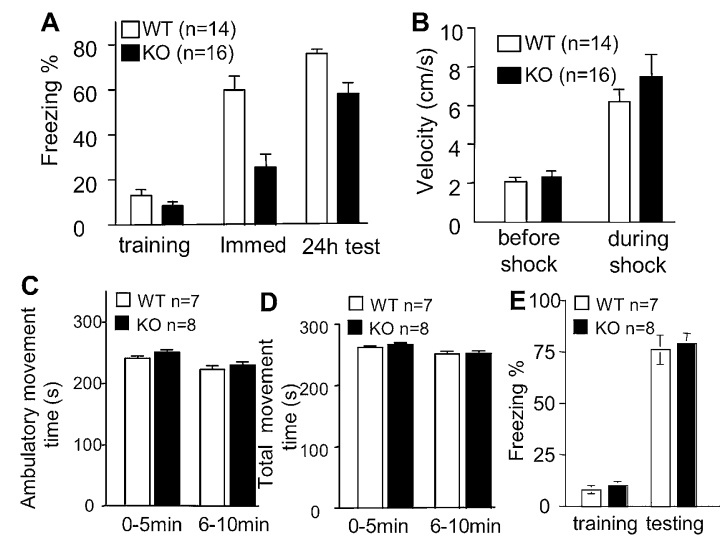

Figure 3. p97FE $65^{-1-}$ mice show defective acquisition in CFC. (A) p97FE $65^{-1-}$ (KO) and WT mice show comparable freezing before the mild footshock (during training). p97FE65 $5^{-1}$ mice showed less freezing (immediate freezing) after the footshock. $\mathrm{p} 97 \mathrm{FE} 65^{-1-}$ mice also showed less freezing $24 \mathrm{~h}$ after the training. $(B)$ p97FE $65^{-1-}$ mice and WT mice show comparable reaction during the footshock. Both genotypes show similar low velocity before the mild electric footshock. The velocity increased significantly during the footshock for both WT and p97FE $65^{-l}$ mice. $(C, D)$ The animals were introduced to the CFC training chamber for $10 \mathrm{~min}$, and the time for ambulatory movement (C) or total movement $(D)$ was measured by the TruScan system. Data for the first 5 min or last 5 min are shown. (E) p97FE65 $5^{-1-}$ mice showed normal freezing when they were tested $24 \mathrm{~h}$ after the hippocampus-independent CFC training.

p97FE65 ${ }^{-1-}$ mice. However, p97FE65 ${ }^{-1-}$ mice displayed significantly less immediate freezing, indicating impaired acquisition/ learning $(P<0.01$, analysis with both two-way ANOVA and Bonferroni post-test; Fig. 3A). When tested $24 \mathrm{~h}$ after training, p97FE65 ${ }^{-1-}$ mice still showed significant impairments in freezing $(P<0.05$, analysis with both two-way ANOVA and Bonferroni post-test; Fig. 3A). To rule out that the defective CFC learning was not due to altered basal activities, we measured animal movement in the CFC training chamber. As shown in Figure 3, C and D, p97FE65 ${ }^{-1-}$ mice showed normal ambulatory movement and total movement. Next, we trained the animals by a hippocampusindependent CFC paradigm, during which mice received three mild footshocks (Wiltgen et al. 2006). When tested $24 \mathrm{~h}$ after training, p97FE65 $5^{-/-}$mice displayed comparable freezing to that of WT mice (Fig. 3E).

\section{p97FE65 $5^{-I-}$ mice show impairments for E-LTP in vivo}

To examine synaptic plasticity and the cellular correlates of learning, we examined in vivo E-LTP. We placed stimulating and recording electrodes in anesthetized animals and recorded the excitatory postsynaptic potentials at the Schaffer collateral-CA1 synapses of the hippocampus. Our in vivo electrophysiological results showed comparable input-output curves in WT and p97FE $65^{-1-}$ mice, indicating normal basal neural transmission (Fig. 4A). Two-way repeated-measures ANOVA indicated that there was no significant effect of genotype $\left(F_{(1,22)}=1.2, P=0.3\right)$ and the interaction between genotype and stimulation intensity $\left(F_{(7,154)}=\right.$ $0.6, P=0.8$ ) on the input-output curve (Fig. $4 \mathrm{~A}$ ). There was also no significant effect of genotype $\left(F_{(1,22)}=0.14, P=0.7\right)$ on pairedpulse facilitation (PPF) (Fig. 4B).

It has been demonstrated that acquisition and E-LTP may share similar mechanisms. They are independent of de novo transcription and translation. We examined WT and p97FE65 ${ }^{-1-}$ mice with E-LTP induced by a single train of high frequency stimulation (HFS). Compared with WT mice, potentiation in p97FE65 ${ }^{-1-}$ mice was significantly diminished within $60 \mathrm{~min}$ after induction
$(P=0.026$; Fig. 4C). These results suggest that $\mathrm{p} 97$ functions in short-term plasticity, which correlates with the impaired learning/ acquisition in the isoform-specific $\mathrm{p} 97 \mathrm{FE} 65^{-/-}$mice.

\section{Acute knockdown of FE65 by siRNA leads to defective learning in TDPA}

To specifically reduce the expression of FE65 in the hippocampus, we infused FE65 siRNA to the dorsal hippocampus. We first demonstrated that the siRNA could effectively reduce both p97 and p60 by $>70 \% 48 \mathrm{~h}$ after administration (Fig. 5A). We next trained the animals by TDPA $48 \mathrm{~h}$ after hippocampal infusion with control or FE65 siRNA. When tested 10 min after training, the FE65 siRNA-infused mice showed significantly shorter crossover latency (Fig. 5B).

\section{Inhibition of phosphodiesterase activity rescues the} learning deficits in the isoform-specific $\mathrm{p} 97 \mathrm{FE} 65^{-I-}$ mice As described earlier, we showed that the hippocampal morphology, as well as the expression levels of neuronal and synaptic marker proteins, is normal in p97FE65 ${ }^{-1-}$ mice. To further test whether some of the plasticity-related signaling pathways are intact in p97FE65 $5^{-1-}$ mice, we administered rolipram to elevate cAMP signaling. Rolipram is a specific inhibitor of the type 4 phosphodiesterase (PDE4), and it enhances the activity of cAMP/ PKA/CREB and LTP (Vitolo et al. 2002; Gong et al. 2004). Compared with the vehicle-injected control, rolipram-injected p97FE65 $5^{-/-}$mice showed significant improvement in TDPA. The crossover latency (tested $10 \mathrm{~min}$ after training) in the rolipraminjected p97FE65 ${ }^{-1-}$ mice was comparable to that of the WT mice (Fig. 6A). These data demonstrate that the function of an FE65independent signal transduction pathway is intact in $\mathrm{p} 97 \mathrm{FE} 65^{-1-}$ mice. Interestingly, rolipram treatment rescues memory deficits in a mouse model for AD (Gong et al. 2004). We also found that rolipram caused potentiation of fEPSP (Fig. 6B,C). However, administration of rolipram did not rescue the HFS-induced E-LTP
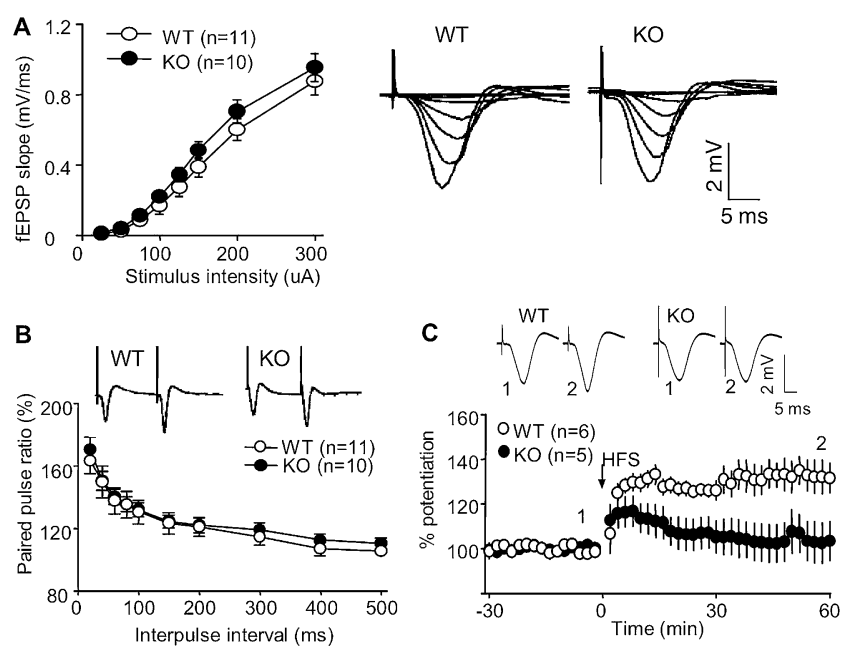

Figure 4. $\mathrm{p} 97 \mathrm{FE} 65^{-1-}$ mice show defective in vivo E-LTP induced by a single tetanus. The field EPSP at the Schaffer collateral-CA1 synapses was recorded from anesthetized WT and p97FE65 ${ }^{-1-}$ (KO) mice. $(A)$ p97FE $65^{-1-}$ and WT mice show comparable input-output curves. (Right) Representative traces of fEPSP from WT and p97FE65 ${ }^{-1-}$ (KO) mice. (B) p97FE $65^{-1-}$ and WT mice show comparable PPF. Representative traces for PPF (with 80-msec interval) are shown. (C) Early-phase LTP (E-LTP) was induced by a single train of HFS (100 Hz, 1-sec duration). p97FE65 ${ }^{-1-}$ mice showed lower potentiation. Representative traces before HFS (trace 1) and 60 min after HFS (trace 2) are shown. 


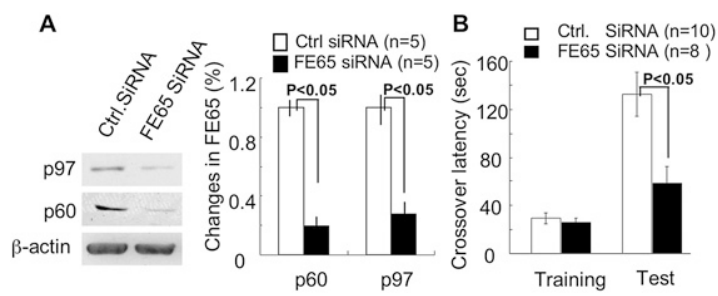

Figure 5. siRNA-mediated knockdown of FE65 results in short-term memory deficits for TDPA. (A) Effective knockdown of FE65 by an siRNA approach. To determine the specific effects of siRNA on FE65 expression, neurons were transfected with control or FE65 siRNA. Samples were collected $48 \mathrm{~h}$ after transfection and analyzed by Western blot. The expression of both p97 and p60 was significantly reduced in neurons transfected with FE65 siRNA. (B) Infusion of FE65 siRNA into the hippocampus results in defective short-term memory of TDPA. Animals infused with control or FE65 siRNA were trained by a single TDPA session and tested $10 \mathrm{~min}$ after training.

in p97FE65 $5^{-/-}$mice; there is not significant further fEPSP potentiation after HFS (Fig. 6B,C). It has been shown that elevating cAMP production by forskolin attenuates memory deficits and potentiates synaptic responses without HFS (Wong et al. 1999). It is possible that rolipram causes partial synaptic saturation and prevents further activity-dependent potentiation. We noticed that the effects of rolipram on in vivo LTP might be different from the in vitro situations. Incubating hippocampal slices with rolipram rescues LTP deficits in aged mice without affecting the baseline values of fEPSP (Barad et al. 1998).

\section{Discussion}

The function of FE65 in learning and memory was addressed with isoform-specific p97FE65 ${ }^{-/-}$mice, which express $\mathrm{p} 60$ but not the full-length $\mathrm{p} 97$. In a previous study, 14 - and 27 -mo-old p97FE65 $5^{-1-}$ mice were compared with their WT littermates. At $14 \mathrm{mo}$, p97FE $65^{-1-}$ mice showed defective performance in TDPA. At 27 mo, p97FE $65^{-1-}$ and WT mice showed similar performance that is significantly worse than 14-mo-old WT mice. Interestingly, the level of p97 but not p60 declined significantly in 27-mo-old WT mice. Because $\mathrm{p} 60$ lacks part of the WW domain, its transcriptional activity is compromised (B Cool, G Zitnik, G Martin, and Q Hu, unpubl.). Therefore, it is suggested that the learning and memory deficits in the isoform-specific p97FE $65^{-1-}$ mice may be due to the lack of activity-dependent transcription mediated by p97. However, the previous study did not test whether $\mathrm{p} 97 \mathrm{FE} 65^{-1-}$ mice were impaired for learning/acquisition or memory consolidation/ retention. To avoid the complication of aging, we examined young adult p97FE65 ${ }^{-1-}$ mice (2-4 mo old) with a battery of hippocampus-dependent paradigms. In the TDPA paradigm, the p97FE65 $5^{-1-}$ mice can eventually learn and reach the cutoff value of crossover latency after multiple training sessions (Fig. 2A). However, they showed significantly less memory retention (Fig. 2B), indicating that $\mathrm{p} 97$ may regulate the transcription of memory-related genes. Because both consolidation and reconsolidation are triggered during the multiple training sessions, it is difficult to determine the function of FE65 in these distinct transcription-dependent processes. Our preliminary experiments detected that membrane depolarization by $\mathrm{KCl}$, which induces calcium influx and gene transcription, stimulated the nuclear translocation of FE65 in primary hippocampal neurons (C Moon and $\mathrm{H}$ Wang, unpubl.). To demonstrate the role of FE65-mediated transcription, future experiments need to identify the target genes of FE65 in stimulated neurons and during memory consolidation/reconsolidation.

Surprisingly, the major deficits with p97FE $65^{-1-}$ mice are related to short-term memory or acquisition, which is a transcription-independent process. Consistently, the isoformspecific p97FE65 ${ }^{-1-}$ mice showed severe impairment in E-LTP at the Schaffer collateral-CA1 synapses. These data suggest that FE65 may be a multifunctional protein that is involved in both transcription-dependent and -independent phases of memory formation. Although cellular studies implicate APP function in transcription, which depends on FE65 (Cao and Sudhof 2001), the existing data suggest that APP may regulate neuronal function in transcription-independent manners. APP KO mice show similar phenotypes to that of p97FE65 $5^{-1-}$ mice. They display impaired acquisition in the conditioned avoidance test and the hidden platform paradigm (Dawson et al. 1999). APP KO mice also show defective potentiation shortly after HFS. When hippocampal slices from APP KO mice were stimulated by four 10-burst trains (at $100 \mathrm{~Hz}$ with a 20 -sec interval), the potentiation started to decline immediately after HFS and was significantly lower than WT controls within 30 min (Dawson et al. 1999; Seabrook et al. 1999).

Analysis of data obtained from $\mathrm{p} 97 \mathrm{FE} 65^{-/-}$and APP KO mice implicates aging/developmental effects. The learning impairments are observed with 10-mo-old, but not 4-mo-old, APP KO mice (Dawson et al. 1999). The LTP impairments are observed with 8- and 20-mo-old APP KO mice (Dawson et al. 1999; Seabrook et al. 1999). LTP in younger APP KO mice has not been examined. Compared with 2 - to 4 -mo-old mice, p97FE $65^{-1-}$ mice show more severe impairments in spatial memory at 14 mo. The 14 -mo-old p97FE $65^{-l-}$ mice show defective acquisition in both hidden platform and reversal training. Although p97FE65 ${ }^{-1-}$ mice (14-mo old) do not show significant defects in the probe test after hidden platform training, they are severely impaired in the probe test after reversal training (Wang et al. 2004a). During reversal training, the animals need to actively suppress the previously established memory, and in the meantime acquire new information to relearn the new platform location. In this study, the young adult p97FE65 ${ }^{-1-}$ mice showed normal time spent in the target quadrant, but we noticed that they took a longer time to reach the platform location during the first probe test (after hidden platform training; data not shown), indicating that the spatial memory in mutant mice may not be as precise as the WT animals. Therefore, memory suppression may be easier for the young adult $\mathrm{p} 97 \mathrm{FE} 65^{-1-}$
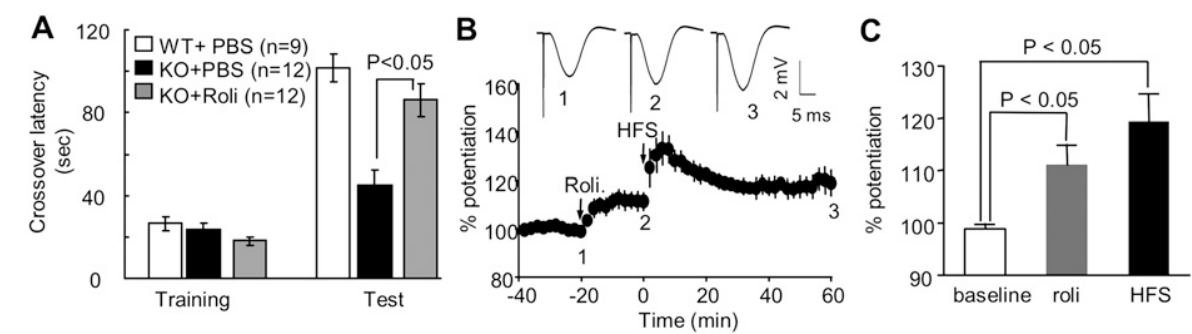

Figure 6. PDE4 inhibitor rescues TDPA deficits, but not LTP, in p97FE65 $5^{-1-}(\mathrm{KO})$ mice. $(A)$ Twenty minutes before TDPA training, mice were given rolipram $(0.1 \mathrm{mg} / \mathrm{kg}$ in $1 \%$ DMSO/PBS) or vehicle ( $1 \%$ DMSO/PBS) through i.p. injection. Mice were trained by a single TDPA session. The animals were tested 10 min after training. (B) After baseline fEPSP was established, p97FE65 $5^{-1-}$ mice were given rolipram $(0.1 \mathrm{mg} / \mathrm{kg}$ through i.p. injection). HFS (100 Hz, 1-sec duration) was delivered $20 \mathrm{~min}$ after rolipram administration. fEPSP was recorded for $60 \mathrm{~min}$ after HFS. Representative fEPSP traces before rolipram treatment (trace 1), after rolipram treatment but before HFS (trace 2), and 60 min after HFS (trace 3) are shown. (C) The relative values of fEPSP corresponding to baseline (values for trace 1), rolipram-treated (values for trace 2), and HFS-induced (values for trace 3 ) responses are shown. 
mice, and their performance in the reversal test, as a balanced outcome of old memory suppression and new learning, appeared to be comparable to that of WT mice. It is intriguing that aged p97FE65 $5^{-1-}$ mice are severely impaired for the reversal test (Wang et al. 2004a). One possibility is that the expression of other members of the FE65 family also declines with age. Because the FE65 family members interact with similar sets of signaling molecules, including APP (McLoughlin and Miller 2008), the compensation from FE65L1 and FE65L2 in p97FE65 ${ }^{-1-}$ mice may dramatically diminish following aging.

How could APP and FE65 regulate the transcription-independent events involved in plasticity? One possibility is that the basal level of certain plasticity-related gene products is lower in APP KO and p97FE $65^{-1-}$ mice. Alternatively, it has been shown that both APP and FE65 are localized in the nerve terminals and are associated with the actin-rich lamellepodia in the growth cones (Sabo et al. 2003), suggesting their function in neurite growth and synapse modification. Consistently, APP-containing membranous cargos undergo rapid axonal transport (Lazarov et al. 2005). Moreover, knocking down presynaptic APP impairs synaptic activity (Herard et al. 2006). FE65 may also regulate synaptic plasticity by regulating $A \beta$ production and secretion (Sabo et al. 1999; Wang et al. 2004a). Compared with Tg2576 neurons, which overexpress a human APP mutant, the levels of $A \beta 40$ and $A \beta 42$ are significantly reduced in p97FE65 $5^{-/} / \mathrm{Tg} 2576$ double-transgenic neurons. Although exogenous application of $\mathrm{A} \beta$ (at $200 \mathrm{nM}$ ) impairs LTP, a slight increase of $A \beta$ (at $200 \mathrm{pM}$ ) enhances both LTP and spatial memory (Puzzo et al. 2008). Future experiments need to determine whether the endogenous $A \beta$ is lower, and whether application of picomolar A $\beta$ rescues the LTP and learning in p97FE65 $5^{-1-}$ mice.

FE65 may regulate neuronal function in an APP-independent manner, and vice versa. At least, the FE65 family members interact with all members of the APP family (Bressler et al. 1996; Guenette et al. 2006). Although MAP2 staining revealed no significant difference between WT and p97FE65 ${ }^{-1-}$ mice, APP KO mice showed abnormality in neuronal morphology and development (Seabrook et al. 1999). Other lines of evidence also imply that the interaction between FE65 and other cellular components may be functionally relevant. For example, the FE65/FE65L1 double-KO and Mena KO mice share some common phenotypes, such as heterotopic neurons and defects in axon pathfinding (McLoughlin and Miller 2008). Many other FE65-interacting proteins have been shown to regulate neuroplasticity under nonpathological conditions. LRP may regulate LTP through its binding to tissue plasminogen activator (Zhuo et al. 2000). ApoE receptors are required for both LTP and CFC (Weeber et al. 2002). Interestingly, FE65 also interacts with the intracellular domain of Notch, and it has been suggested that Notch and APP may regulate a number of same target genes (Fischer et al. 2005). Mice with a reduced level of Notch display defects in both LTP and spatial learning (Costa et al. 2003; Wang et al. 2004b). Because certain regulatory functions may be shared by FE65s (FE65, FE65L1, and FE65L2), using neurons derived from double- or triple-mutants will facilitate the understanding of how the FE65 family participates in the complex signaling network.

\section{Materials and Methods}

\section{Animals}

Isoform-specific FE65 mutant mice (p97FE65 ${ }^{-/-}$) were generated by conventional gene-specific recombination by replacing exon 2 with a neo cassette and backcrossing into the C57BL/6 background for at least 10 generations. p97FE65 $5^{-1-}$ mice were previously characterized, and the expression of p97, but not p60, was ablated (Wang et al. 2004a). Animals were housed in the University Laboratory Animal Research Facility, and all the manipulations were in compliance with the guidelines of Institutional Animal Care and Use Committee at Michigan State University. The mice had ad libitum access to water and food and were housed under 12-h dark/light cycles.

\section{Analysis of hippocampal morphology}

Fresh whole brains were obtained from age-matched WT and p97FE65 ${ }^{-1-}$ mice (2-4 mo old), and then cut into 0.5-mm-thick coronal slices by a vibratome. The slices were immediately fixed in PBS with $6 \%$ paraformaldehyde, $50 \mathrm{mM}$ HEPES $\mathrm{pH} 7.6$ for $6 \mathrm{~h}$, subsequently cryoprotected with $20 \%$ sucrose/PBS for $24 \mathrm{~h}$, and further processed by a sliding microtome to obtain $40-\mu \mathrm{m}$-thick slices. Overall hippocampal histological analysis was performed by Neutral Red staining. Mossy fiber formation was stained by antibodies against Calbindin (1:1000). Antibodies against microtubuleassociated protein 2 (MAP2) (1:500) were used to compare the neuron numbers between WT and p97FE65 ${ }^{-1-}$ mice. Antibodies against synapsin I (1:500) and vesicular GABA transporter (VGAT) (1:1000) were used to stain general presynaptic and inhibitory presynaptic markers, respectively. The incubation for primary and secondary (rhodamine red-conjugated) antibodies was $2 \mathrm{~h}$ in PBS with $0.1 \%$ triton $\mathrm{X}-100,3 \% \mathrm{BSA}$, and $3 \%$ crude serum at room temperature. The samples were then examined with fluorescence detection by confocal microscopy.

\section{Morris water maze (MWM)}

The MWM was used for testing hippocampus-dependent spatial memory (Morris et al. 1982). Animal activity was measured by a video-based tracking system (WaterMaze; Coulbourn Instruments). The pool was filled with opaque water (by adding washable white paint) and surrounded by extramaze cues. The escape platform $(10 \mathrm{~cm}$ in diameter) was placed in the center of a designated quadrant with its top positioned $1 \mathrm{~cm}$ below the water surface. During the visible platform training, the platform was marked by a flag, and mice were trained by four trials per day for $2 \mathrm{~d}$. In the hidden-platform test, mice were first trained daily by two trials with a 4-h interval for $9 \mathrm{~d}$. A probe test was given on day 10. At the beginning of each trial, mice were pseudorandomly dropped at one of the six start points. Mice were allowed to swim freely until they climbed onto the platform and stayed on the platform for $20 \mathrm{sec}$. If mice were unable to find the platform within $90 \mathrm{sec}$, they were guided to the platform and allowed to stay on the platform for $20 \mathrm{sec}$. During the probe test, the hidden platform was removed from the pool, and mice were allowed to swim for $60 \mathrm{sec}$. The time spent in each quadrant, as well as the number of platform crossings, was recorded. For the reversal task, the hidden platform was moved to the opposite quadrant. Mice were trained daily by two trials with a 4-h interval for $3 \mathrm{~d}$. A probe test was performed on day 4 .

\section{Temporal dissociative passive avoidance (TDPA)}

Training and testing for the TDPA paradigm was performed as described (Zhang et al. 2008). During training, the mouse was introduced to the lit half of the training chamber (Coulbourn Instruments) and allowed to explore for $1 \mathrm{~min}$ before the trap door was opened. After the animal entered the dark chamber, the trap door was closed and a mild footshock $(0.7 \mathrm{~mA}$ for $2 \mathrm{sec})$ was delivered $10 \mathrm{~min}$ later. The animal was returned to its home cage 20 sec after the footshock. When tested, the trained mouse was reintroduced to the lit chamber. The time spent in the lit chamber before entering the dark chamber was scored as crossover latency and used as the index for memory formation. We chose $300 \mathrm{sec}$ as the cutoff value for crossover latency. For the experiments in Figure $2 \mathrm{~A}$, animals were trained on day 1 and tested daily on days $2-6$. On days $2-5$, mice were first scored for crossover latency. They were then shocked $10 \mathrm{~min}$ after they entered the dark chamber. Therefore, the animals were also trained following the scoring. For the experiments in Figure 2D, the animals were trained once, tested 10 min after the training, and crossover latency was recorded. 


\section{Dark/light test}

The same PA chamber and lighting conditions were used for the dark/light test as described previously (Krishnan et al. 2008). A mouse was introduced to the dark chamber and habituated for $2 \mathrm{~min}$ before the trap door was opened. The animals were allowed to move between the dark and lit chamber for $10 \mathrm{~min}$. The latency of animals' initial crossover to the lit chamber was recorded. The total time spent in the lit and dark chamber was also scored.

\section{Contextual fear conditioning (CFC)}

During training, mice were placed in the operant chamber with a metal grid floor for $30 \mathrm{sec}$ (TruScan chamber with photobeam sensors; Coulbourn Instruments), after which a mild electric footshock was delivered ( $0.7 \mathrm{~mA}$ with 2 -sec duration). Mice stayed in the training chamber for another $30 \mathrm{sec}$, during which "immediate freezing" was scored. Twenty-four hours after training, mice were tested and scored for freezing. The freezing behavior, defined by immobility except for breathing, was scored once every $5 \mathrm{sec}$ for $3 \mathrm{~min}$. The movement velocity before and during the mild electric footshock was monitored by the TruScan system. To measure the hippocampus-independent CFC memory (Wiltgen et al. 2006), a mouse was placed into the training chamber for $2 \mathrm{~min}$ before receiving three mild electric footshocks (1.5 mA, 2-sec duration) delivered once every $2 \mathrm{~min}$. The animals remained in the training chamber for $30 \mathrm{sec}$ after the last shock and were returned to their home cages. The animals were tested $24 \mathrm{~h}$ after training, and the percentage of freezing was scored.

\section{In vivo extracellular recording}

Naïve male mice (2-4 mo of age) were anesthetized with sodium pentobarbital (100 $\mathrm{mg} / \mathrm{kg}$, i.p.), and placed in a stereotaxic frame (David Kopf). Recording and stimulating electrodes were made of a pair of Teflon-coated PT/IR wires $(50 \mu \mathrm{m}$ inner diameter, $100 \mu \mathrm{m}$ outer diameter, World Precision Instruments, Inc; cat. no. PTT0110). The coordinates for the recording electrode in the CA1 region were $\mathrm{AP}=-1.7-1.9 \mathrm{~mm}, \mathrm{ML}=1.2 \mathrm{~mm}$, and $\mathrm{DV}=$ $1.5-1.9 \mathrm{~mm}$ from skull surface. The stimulating electrode was implanted into the ipsilateral Schaffer collateral fibers $(\mathrm{AP}=$ $-1.7-1.9 \mathrm{~mm}, \mathrm{ML}=1.7 \mathrm{~mm}$, and $\mathrm{DV}=1.6-2.0 \mathrm{~mm}$ from skull surface). Constant current pulses ( $0.10 \mathrm{msec}$ duration) were delivered once every $30 \mathrm{sec}$. After a stable baseline (50\% of maximal fEPSP) was established, E-LTP was induced by a single train of high frequency stimulation (HFS, at $100 \mathrm{~Hz}$ for $1 \mathrm{sec}$ ). The potentiation was calculated by comparing the slope of fEPSP with that of the baseline values. After electrophysiological recordings, electrolytic currents $(4 \mathrm{~mA}, 2 \mathrm{sec})$ were delivered to produce a thermolytic lesion at the electrode tips, which was used for histological confirmation of the electrode placement.

\section{Hippocampal infusion of FE65 siRNA}

Stealth siRNA duplex was purchased from Invitrogen. The sequences for the double-strand siRNA used for mouse FE65 are: CCA GAUGCUCAAGUGCCACGUGUUU (upper strand) and AAACA CGUGGCACUUGAGCAUCUGG (lower strand). For the control duplex siRNA, sequences with the same GC content are scrambled. First, $300 \mu \mathrm{g}$ of double-strand siRNA was annealed in $1.4 \mathrm{~mL}$ of annealing buffer $(10 \mathrm{mM}$ Tris- $\mathrm{HCl}, \mathrm{pH} 8.0,20 \mathrm{mM} \mathrm{NaCl}, 1 \mathrm{mM}$ EDTA) and then precipitated (after adjusting the solution to $0.3 \mathrm{M}$ sodium acetate and $10 \%$ isopropanol). Before transfection or hippocampal infusion, the precipitate was washed by ice-cold $70 \%$ ethanol, dried, and resuspended in PBS at $10 \mu \mathrm{g} / \mu \mathrm{L}$. For hippocampal infusion, $1 \mu \mathrm{L}$ of double-stranded siRNA was mixed with $0.5 \mu \mathrm{L}$ of Lipofectamine 2000 (Invitrogen) for $30 \mathrm{~min}$ at room temperature (Gavrila et al. 2008). After deep anesthetization, the siRNA was delivered through a 30 -gauge needle $(1.5 \mu \mathrm{L}$ for each side of the hippocampus at $0.15 \mu \mathrm{L} / \mathrm{min}$ ) to the dorsal hippocampus. The stereotaxic coordinates for injection are: $\mathrm{AP}=-1.9 \mathrm{~mm}$, $\mathrm{ML}=1.6 \mathrm{~mm}$, and DV $=2.0 \mathrm{~mm}$ from skull surface. Forty-eight hours after injection, mice were trained by TDPA. The transfection of siRNA to neurons was performed as described previously (Bhargava et al. 2004; Dalby et al. 2004). Forty-eight hours after transfection, the effects of siRNA on FE65 expression were analyzed by Western blot analysis. A polyclonal rabbit antibody (FE518) was used to detect both p97 and p60 isoforms of FE65 (Wang et al. 2004a).

\section{Data analysis}

Two-way repeated-measures ANOVA was used for analyzing MWM, CFC (followed by Bonferroni post-test), and TDPA data (genotype and time/trial as between-/within-subject factor). The Student's $t$-test was used to assess significance for data between two groups. Data were expressed as the average \pm SEM. Differences with $P$-values $<0.05$ were considered statistically significant.

\section{Acknowledgments}

This study was supported by the American Federation of Aging Research (H.W.). Y.W. was supported by the China Scholarship Council (CSC). Z.S. was supported by the Chinese Academy of Sciences innovation project (KSCX2-YW-R-38).

\section{References}

Barad M, Bourtchouladze R, Winder DG, Golan H, Kandel E. 1998 Rolipram, a type IV-specific phosphodiesterase inhibitor, facilitates the establishment of long-lasting long-term potentiation and improves memory. Proc Natl Acad Sci 95: 15020-15025.

Bhargava A, Dallman MF, Pearce D, Choi S. 2004. Long double-stranded RNA-mediated RNA interference as a tool to achieve site-specific silencing of hypothalamic neuropeptides. Brain Res Brain Res Protoc 13: $115-125$.

Borg JP, Ooi J, Levy E, Margolis B. 1996. The phosphotyrosine interaction domains of X11 and FE65 bind to distinct sites on the YENPTY motif of amyloid precursor protein. Mol Cell Biol 16: 6229-6241.

Bork P, Margolis B. 1995. A phosphotyrosine interaction domain. Cell 80: 693-694.

Bressler SL, Gray MD, Sopher BL, Hu Q, Hearn MG, Pham DG, Dinulos MB, Fukuchi K, Sisodia SS, Miller MA, et al. 1996. cDNA cloning and chromosome mapping of the human Fe65 gene: Interaction of the conserved cytoplasmic domains of the human $\beta$-amyloid precursor protein and its homologues with the mouse Fe65 protein. Hum Mol Genet 5: 1589-1598.

Cao X, Sudhof TC. 2001. A transcriptionally [correction of transcriptively] active complex of APP with Fe65 and histone acetyltransferase Tip60. Science 293: 115-120.

Chen HI, Sudol M. 1995. The WW domain of Yes-associated protein binds a proline-rich ligand that differs from the consensus established for Src homology 3-binding modules. Proc Natl Acad Sci 92: 7819-7823.

Costa RM, Honjo T, Silva AJ. 2003. Learning and memory deficits in Notch mutant mice. Curr Biol 13: 1348-1354.

Dalby B, Cates S, Harris A, Ohki EC, Tilkins ML, Price PJ, Ciccarone VC. 2004. Advanced transfection with Lipofectamine 2000 reagent: Primary neurons, siRNA, and high-throughput applications. Methods 33: 95103.

Dawson GR, Seabrook GR, Zheng H, Smith DW, Graham S, O'Dowd G, Bowery BJ, Boyce S, Trumbauer ME, Chen HY, et al. 1999. Age-related cognitive deficits, impaired long-term potentiation and reduction in synaptic marker density in mice lacking the $\beta$-amyloid precursor protein. Neuroscience 90: 1-13.

Ermekova KS, Zambrano N, Linn H, Minopoli G, Gertler F, Russo T, Sudol M. 1997. The WW domain of neural protein FE65 interacts with prolinerich motifs in Mena, the mammalian homolog of Drosophila enabled. J Biol Chem 272: 32869-32877.

Fiore F, Zambrano N, Minopoli G, Donini V, Duilio A, Russo T. 1995. The regions of the Fe65 protein homologous to the phosphotyrosine interaction/phosphotyrosine binding domain of Shc bind the intracellular domain of the Alzheimer's amyloid precursor protein. J Biol Chem 270: 30853-30856.

Fischer DF, van Dijk R, Sluijs JA, Nair SM, Racchi M, Levelt CN, van Leeuwen FW, Hol EM. 2005. Activation of the Notch pathway in Down syndrome: Cross-talk of Notch and APP. FASEB J 19: 1451-1458.

Gavrila AM, Robinson B, Hoy J, Stewart J, Bhargava A, Amir S. 2008. Doublestranded RNA-mediated suppression of Period2 expression in the suprachiasmatic nucleus disrupts circadian locomotor activity in rats. Neuroscience 154: 409-414.

Gong B, Vitolo OV, Trinchese F, Liu S, Shelanski M, Arancio O. 2004. Persistent improvement in synaptic and cognitive functions in an Alzheimer mouse model after rolipram treatment. J Clin Invest 114: 1624-1634. 
Guenette SY, Chen J, Jondro PD, Tanzi RE. 1996. Association of a novel human FE65-like protein with the cytoplasmic domain of the $\beta$-amyloid precursor protein. Proc Natl Acad Sci 93: 10832-10837.

Guenette S, Chang Y, Hiesberger T, Richardson JA, Eckman CB, Eckman EA, Hammer RE, Herz J. 2006. Essential roles for the FE65 amyloid precursor protein-interacting proteins in brain development. EMBO J 25: 420-431.

Heber S, Herms J, Gajic V, Hainfellner J, Aguzzi A, Rulicke T, von Kretzschmar H, von Koch C, Sisodia S, Tremml P, et al. 2000. Mice with combined gene knock-outs reveal essential and partially redundant functions of amyloid precursor protein family members. J Neurosci 20: 7951-7963.

Herard AS, Besret L, Dubois A, Dauguet J, Delzescaux T, Hantraye P, Bonvento G, Moya KL. 2006. siRNA targeted against amyloid precursor protein impairs synaptic activity in vivo. Neurobiol Aging 27: 1740-1750.

Hoe HS, Magill LA, Guenette S, Fu Z, Vicini S, Rebeck GW. 2006. FE65 interaction with the ApoE receptor ApoEr2. J Biol Chem 281: 24521-24530.

Hu Q, Jin LW, Starbuck MY, Martin GM. 2000. Broadly altered expression of the mRNA isoforms of FE65, a facilitator of $\beta$ amyloidogenesis, in Alzheimer cerebellum and other brain regions. J Neurosci Res 60: 73-86.

Hu Q, Cool BH, Wang B, Hearn MG, Martin GM. 2002. A candidate molecular mechanism for the association of an intronic polymorphism of FE65 with resistance to very late onset dementia of the Alzheimer type. Hum Mol Genet 11: 465-475.

Ikin AF, Sabo SL, Lanier LM, Buxbaum JD. 2007. A macromolecular complex involving the amyloid precursor protein (APP) and the cytosolic adapter FE65 is a negative regulator of axon branching. Mol Cell Neurosci 35: $57-63$.

Kesavapany S, Banner SJ, Lau KF, Shaw CE, Miller CC, Cooper JD, McLoughlin DM. 2002. Expression of the Fe65 adapter protein in adult and developing mouse brain. Neuroscience 115: 951-960.

Kimberly WT, Esler WP, Ye W, Ostaszewski BL, Gao J, Diehl T, Selkoe DJ, Wolfe MS. 2003. Notch and the amyloid precursor protein are cleaved by similar $\gamma$-secretase(s). Biochemistry 42: 137-144.

Kinoshita A, Whelan CM, Smith CJ, Mikhailenko I, Rebeck GW, Strickland DK, Hyman BT. 2001. Demonstration by fluorescence resonance energy transfer of two sites of interaction between the low-density lipoprotein receptor-related protein and the amyloid precursor protein: Role of the intracellular adapter protein Fe65. J Neurosci 21: 8354-8361.

Krishnan V, Graham A, Mazei-Robison MS, Lagace DC, Kim KS, Birnbaum S Eisch AJ, Han PL, Storm DR, Zachariou V, et al. 2008. Calcium-sensitive adenylyl cyclases in depression and anxiety: Behavioral and biochemical consequences of isoform targeting. Biol Psychiatry 64: 336-343.

Lazarov O, Morfini GA, Lee EB, Farah MH, Szodorai A, DeBoer SR, Koliatsos VE, Kins S, Lee VM, Wong PC, et al. 2005. Axonal transport, amyloid precursor protein, kinesin-1, and the processing apparatus: Revisited. J Neurosci 25: 2386-2395.

McLoughlin DM, Miller CC. 2008. The FE65 proteins and Alzheimer's disease. J Neurosci Res 86: 744-754.

Morris RG, Garrud P, Rawlins JN, O'Keefe J. 1982. Place navigation impaired in rats with hippocampal lesions. Nature 297: 681-683.

Muller T, Concannon CG, Ward MW, Walsh CM, Tirniceriu AL, Tribl F, Kogel D, Prehn JH, Egensperger R. 2007. Modulation of gene expression and cytoskeletal dynamics by the amyloid precursor protein intracellular domain (AICD). Mol Biol Cell 18: 201-210.

Muller T, Meyer HE, Egensperger R, Marcus K. 2008. The amyloid precursor protein intracellular domain (AICD) as modulator of gene expression, apoptosis, and cytoskeletal dynamics-relevance for Alzheimer's disease. Prog Neurobiol 85: 393-406.

Puzzo D, Privitera L, Leznik E, Fa M, Staniszewski A, Palmeri A, Arancio O. 2008 . Picomolar amyloid- $\beta$ positively modulates synaptic plasticity and memory in hippocampus. J Neurosci 28: 14537-14545.
Sabo SL, Lanier LM, Ikin AF, Khorkova O, Sahasrabudhe S, Greengard P, Buxbaum JD. 1999. Regulation of $\beta$-amyloid secretion by FE65, an amyloid protein precursor-binding protein. J Biol Chem 274: 7952-7957.

Sabo SL, Ikin AF, Buxbaum JD, Greengard P. 2003. The amyloid precursor protein and its regulatory protein, FE65, in growth cones and synapses in vitro and in vivo. $J$ Neurosci 23: 5407-5415.

Schroeter EH, Kisslinger JA, Kopan R. 1998. Notch-1 signalling requires ligand-induced proteolytic release of intracellular domain. Nature 393: 382-386.

Seabrook GR, Smith DW, Bowery BJ, Easter A, Reynolds T, Fitzjohn SM, Morton RA, Zheng H, Dawson GR, Sirinathsinghji DJ, et al. 1999. Mechanisms contributing to the deficits in hippocampal synaptic plasticity in mice lacking amyloid precursor protein. Neuropharmacology 38: $349-359$.

Suzuki T, Araki Y, Yamamoto T, Nakaya T. 2006. Trafficking of Alzheimer's disease-related membrane proteins and its participation in disease pathogenesis. J Biochem 139: 949-955.

Vitolo OV, Sant'Angelo A, Costanzo V, Battaglia F, Arancio O, Shelanski M. 2002. Amyloid $\beta$-peptide inhibition of the PKA/CREB pathway and long-term potentiation: Reversibility by drugs that enhance cAMP signaling. Proc Natl Acad Sci 99: 13217-13221.

von Rotz RC, Kohli BM, Bosset J, Meier M, Suzuki T, Nitsch RM, Konietzko U. 2004. The APP intracellular domain forms nuclear multiprotein complexes and regulates the transcription of its own precursor. J Cell Sci 117: $4435-4448$.

Wang B, Hu Q, Hearn MG, Shimizu K, Ware CB, Liggitt DH, Jin LW, Coo BH, Storm DR, Martin GM. 2004a. Isoform-specific knockout of FE65 leads to impaired learning and memory. J Neurosci Res 75: 12-24.

Wang Y, Chan SL, Miele L, Yao PJ, Mackes J, Ingram DK, Mattson MP, Furukawa K. 2004b. Involvement of Notch signaling in hippocampal synaptic plasticity. Proc Natl Acad Sci 101: 9458-9462.

Weeber EJ, Beffert U, Jones C, Christian JM, Forster E, Sweatt JD, Herz J. 2002. Reelin and ApoE receptors cooperate to enhance hippocampal synaptic plasticity and learning. J Biol Chem 277: 39944-39952.

Wiltgen BJ, Sanders MJ, Anagnostaras SG, Sage JR, Fanselow MS. 2006. Context fear learning in the absence of the hippocampus. J Neurosci 26: 5484-5491.

Wong ST, Athos J, Figueroa XA, Pineda VV, Schaefer ML, Chavkin CC, Muglia LJ, Storm DR. 1999. Calcium-stimulated adenylyl cyclase activity is critical for hippocampus-dependent long-term memory and late phase LTP. Neuron 23: 787-798.

Yang Z, Cool BH, Martin GM, Hu Q. 2006. A dominant role for FE65 (APBB1) in nuclear signaling. J Biol Chem 281: 4207-4214.

Zambrano N, Buxbaum JD, Minopoli G, Fiore F, De Candia P, De Renzis S, Faraonio R, Sabo S, Cheetham J, Sudol M, et al. 1997. Interaction of the phosphotyrosine interaction/phosphotyrosine binding-related domains of Fe65 with wild-type and mutant Alzheimer's $\beta$-amyloid precursor proteins. J Biol Chem 272: 6399-6405.

Zambrano N, Minopoli G, de Candia P, Russo T. 1998. The Fe65 adaptor protein interacts through its PID1 domain with the transcription factor CP2/LSF/LBP1. J Biol Chem 273: 20128-20133.

Zhang M, Moon C, Chan GC, Yang L, Zheng F, Conti AC, Muglia L, Muglia LJ, Storm DR, Wang H. 2008. Ca-stimulated type 8 adenylyl cyclase is required for rapid acquisition of novel spatial information and for working/episodic-like memory. J Neurosci 28: 4736-4744.

Zhuo M, Holtzman DM, Li Y, Osaka H, DeMaro J, Jacquin M, Bu G. 2000. Role of tissue plasminogen activator receptor LRP in hippocampal longterm potentiation. J Neurosci 20: 542-549.

Received June 8, 2009; accepted in revised form July 14, 2009. 


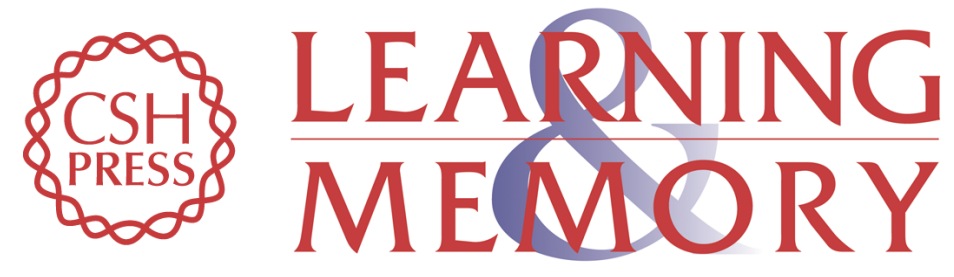

\section{The APP-interacting protein FE65 is required for hippocampus-dependent learning and long-term potentiation}

Yan Wang, Ming Zhang, Changjong Moon, et al.

Learn. Mem. 2009, 16:

Access the most recent version at doi:10.1101//m.1499309

References This article cites 50 articles, 25 of which can be accessed free at: http://learnmem.cshlp.org/content/16/9/537.full.html\#ref-list-1

License

Email Alerting Receive free email alerts when new articles cite this article - sign up in the box at the Service top right corner of the article or click here. 